\title{
Illumination of Contributing Parameters of Uneven Break in Narrow Vein Mine
}

\author{
Hyongdoo Jang ${ }^{1}$, Sina Taheri ${ }^{1}$, Erkan Topal ${ }^{1}$, and Youhei Kawamura ${ }^{2}$ \\ 1 \\ Western Australian School of Mines, Curtin University, \\ Kalgoorlie, WA, Australia \\ hyongdoo.jang@curtin.edu.au \\ Graduate School of International Resource Sciences, \\ Department of Earth Resource Engineering and Environmental Science, Akita University, Akita, Japan
}

\begin{abstract}
One of the principal challenge facing the stope production in underground mining is the overbreak and underbreak (UB: uneven break). Although the UB features a critical economic fallout to the entire mining process, it is much inevitable and usually left as an unpredictable phenomenon in underground mines. The complex mechanism of UB must be examined to minimize the UB phenomenon. In this study, the contribution of ten primary UB causative parameters is scrutinized investigating a published UB prediction ANN model. The inputs (UB causative factors) contributions to the output (percentage of UB) of the ANN model were analyzed using Profile methodology (PM). The results PM revealed the essential importance of geological parameters to UB phenomenon as the calculated contributions of adjusted Q-rate (GAQ) and average horizontal to vertical stress ratio (GSK) are $20.48 \%$ and $18.12 \%$ respectively. Also, the trends of the other eight UB causative factors were investigated. The findings of this study can be used as a reference in stope design and reconciliation processes to maximize the productivity of the underground mine.
\end{abstract}

Keywords: Overbreak Underbreak Narrow vein ANN

\section{Introduction}

In the modern mining industry, many underground metalliferous mines are operating by various type of stoping methods due to the flexible applicability over various ground conditions and the ability to mechanization into large scale. Pakalins noted that in 1996, 50\% underground metalliferous mines were operating by open stoping method and in 2011, over 60\% of underground production in North America was produced by sublevel stoping method (Pakalnis and Hughes 2011). Recently, Jang et al. (2015a) noted that more than 85\% of underground metalliferous mines rely on various stoping methods.

Despite the advantages of stoping method, mines are often suffering from unplanned dilution and ore-loss that inevitably occur at the stope production blasting. The unplanned dilution can be defined as the influx of over broken rocks from beyond the planned stope margin while the unplanned ore-loss is the remaining ore even after the production. In other words, the unplanned dilution and ore-loss are overbreak and underbreak from the blasting engineers' perspective and Jang et al. (2015b) noted them as uneven break (UB). Figure 1 schematically demonstrates the unplanned dilution and ore-loss.

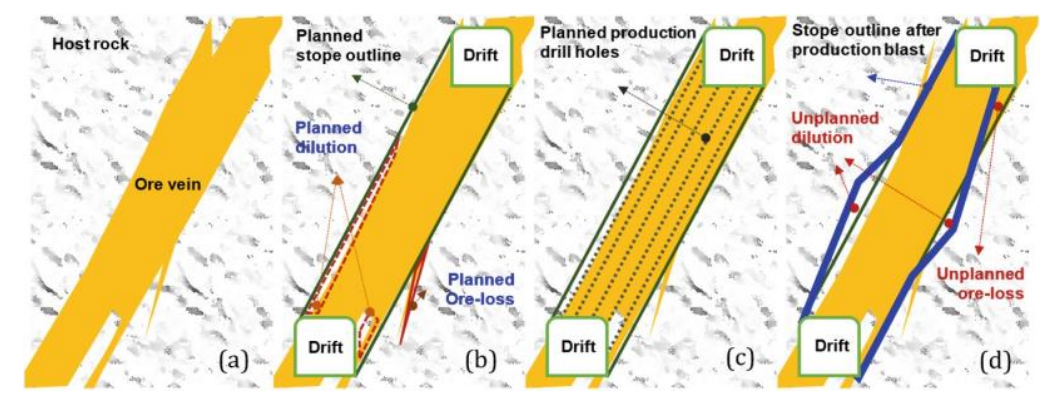

Fig. 1. Schematic view of dilution and ore-loss throughout stope production stages (a) an example of ore vein shape (b) stope production plan (c) production drilling plan (d) stope after production (Jang et al. 2016) 
The overbreak and underbreak (UB: uneven break) directly influence the productivity of a mine. In fact, one of the primary tasks of mining engineers is to minimize UB phenomenon under a manageable level. Thus, understanding of the causative factors and complex UB causing mechanism is essential.

Table 1. The list of ten UB causative factors and corresponding percentage of UB

\begin{tabular}{|c|c|c|c|c|c|c|c|c|c|c|c|}
\hline \multirow[t]{4}{*}{ No. } & \multicolumn{10}{|c|}{ Input parameters } & \multirow{3}{*}{$\begin{array}{l}\text { Output } \\
\text { UBP }\end{array}$} \\
\hline & \multicolumn{5}{|c|}{ Blasting } & \multicolumn{2}{|c|}{ Geology } & \multicolumn{3}{|c|}{ Stope design } & \\
\hline & BHL & BPF & BAN & BHD & BSB & GAQ & GSK & SPT & SAR & SOB & \\
\hline & $\mathrm{m}$ & $\mathrm{Kg} / \mathrm{t}$ & $\circ$ & $\mathrm{mm}$ & $(\mathrm{S} / \mathrm{B})$ & - & $(\mathrm{H} / \mathrm{V})$ & tons & $(\mathrm{W} / \mathrm{H})$ & - & $\%$ \\
\hline 1 & 15.20 & 0.56 & 2.00 & 89 & 1.25 & 37 & 1.85 & 18,480 & 1.65 & 1 & $-2.30 \%$ \\
\hline 2 & 13.50 & 0.42 & 55.00 & 89 & 1.50 & 30 & 1.99 & 4,200 & 2.67 & 1 & $4.70 \%$ \\
\hline 2 & 7.30 & 0.45 & 0.00 & 76 & 1.11 & 40 & 2.12 & 896 & 0.5 & 0 & $3.10 \%$ \\
\hline$\cdots$ & $\cdots$ & $\cdots$ & $\cdots$ & $\cdots$ & $\ldots$ & $\cdots$ &.$\cdot$ & $\cdots$ & & $\cdots$ & $\cdots$ \\
\hline 1065 & 8.00 & 0.68 & 17.00 & 76 & 1.25 & 26 & 2.22 & 2,980 & 0.38 & 0 & $-18.60 \%$ \\
\hline 1066 & 16.60 & 0.91 & 0.00 & 89 & 1.15 & 14 & 3.15 & 16,607 & 0.83 & 1 & $10.10 \%$ \\
\hline 1067 & 20.20 & 0.90 & 0.00 & 89 & 1.20 & 19 & 3.25 & 6,804 & 0.37 & 0 & $12.70 \%$ \\
\hline Min. & 0.70 & 0.15 & 0.00 & 76 & 0.57 & 6.30 & 1.74 & 130 & 0.07 & 0 & -65.40 \\
\hline Max. & 25.80 & 3.00 & 170.20 & 89 & 1.50 & 93.30 & 14.38 & 51,450 & 4.17 & 1 & 92.00 \\
\hline
\end{tabular}

BHL: Average length of blasthole, BPF: Powder factor, BAN: Angle difference between hole and wall, BHD: Diameter of blasthole, BSB: Space (S) and burden (B) ratio, GAQ: Adjusted Q rate, GSK: Average horizontal to vertical stress ratio, SPT: Tons of stope planned, SAR: Aspect ratio of stope, SOB: Opened or blind of the stope UBP: Percentage of uneven break (over and under break)

The study aims to illuminate the complex causing mechanism of UB adopting an UB prediction model published by Jang et al. (2015a). The UB prediction model was developed by investigating 1067 stope production results from underground stoping mines in Western Australia. Each dataset consists of 10 input parameters (UB causative factors) and the corresponding output (measured percentage of overbreak). Five blasting related factors, i.e., average length of blasthole (BHL), powder factor (BPF), angle difference between hole and wall (BAN), diameter of blasthole (BHD), and Space (S) and burden (B) ratio (BSB), two geology parameters, i.e., adjusted Q rate (GAQ), average horizontal to vertical stress ratio (GSK), and two stope design factors, i.e., tons of stope planned (SPT), opened or blind of the stope (SOB) were used as input factors while the corresponding percentage of overbreak and underbreak (UBP) was set as the output in the model. The study relied on the historical data thus human errors, i.e., the drilling errors and the hole deviation were not considered. The influence of human errors in UB phenomenon was indirectly included in the study with the BHL as the drilling accuracy is generally expressed as a percentage of the hole depth (Stiehr and Dean 2011). The list of data sets is shown in Table 1.

\section{Current over and Underbreak Management in Underground Stoping Mines}

Minimising uneven break (UB) in stope production is one of the essential tasks because it is directly influencing not only to the productivity of stope production but also the profit throughout of mining operations. However, UB is challenging to manage due to its highly complex causing mechanism. Many engineers and scholars have been endeavoring to manage the unwanted phenomenon, but the industry often relies on historical stope reconciliation results and intuitions of experienced engineers.

Few empirical systems have introduced and the stability graph method (Mathews et al. 1981; Nickson 1992; Potvin 1988) is widely used to manage the stope overbreak. This method is plotting a stability number (N) against a hydraulic radius (HR: area/perimeter of the stope wall) to judge the stability of stope wall. The stability number is an integrated geotechnical factor that has been modified by Potvin (1988) and is defined as: 
Where $\mathrm{N}^{\prime}$ presents the modified stability number, $\mathrm{Q}^{\prime}$ is the modified $\mathrm{Q}$ value, and $\mathrm{A}, \mathrm{B}$, and $\mathrm{C}$ are factors that stand for the stress, the joint orientation, and the gravity respectively.

The stability of a designed stope wall can be easily assessed with the stability graph method but cannot guarantee a reliable judgment. Considering the complexity of the overbreak and underbreak phenomenon during rock blasting, the stability of a stope wall cannot be adequately assessed with few geotechnical factors in the stability graph method (Jang 2014). For example, Fig. 2 demonstrates 134 cases of stability analysis results with measured overbreak in each data point. Most of the stopes were designed to be in the stable zone in the stability graph but overbreak were randomly occurred.

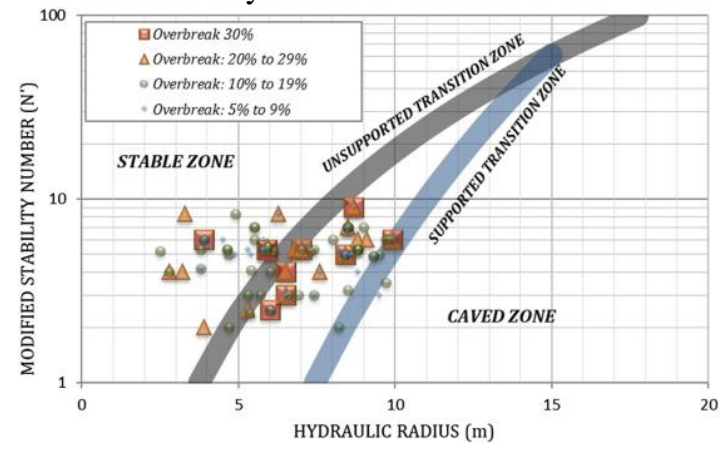

Fig. 2. Stability graph method analysis results and corresponding overbreak results (Jang, 2014)

Germain and Hadjigeorgiou (1997) conducted a study on stope overbreak investigating the powder factor of stope production blast and Q-value (Barton et al. 1974). The study used a linear regression analysis to find the relation between overbreak and the two variables but the result was statistically insignificant as the correlation coefficient of less than 0.3. The stress effects on stope overbreak were investigated by Stewart et al. (2005). The study found the critical influence of stress on the overbreak phenomenon as more than $50 \%$ of overbreak occurred where the induced stress was exceeded the damage criterion. Pakalnis (1986) developed an overbreak prediction model investigating 133 open stope production results in Canada. The model can predict the percentage of overbreak on stope wall investigating the hydraulic radius and rock mass rating (RMR) (Bieniawski 1973, 1974) in three different stope conditions, i.e., isolated, adjacent rib, and echelon. Lang (1994) introduced the critical span cave method to analyze the stability of the cut and fill stoping mines and updated including 292 case studies in the University of British Colombia. In the study, the critical span was defined as the diameter of the largest circle of unsupported back in the stope and the stability of a stope back was determined by plotting designed critical span of the stope with the RMR value. The method has been used in some Canadian mines but it requires careful consideration as it founded with regional data. Despite the endeavors of many researchers, the causing mechanism and the exact contributions of causing parameters of over and underbreak are not studied.

\section{UB Prediction ANN Model}

In this study, artificial neural network (ANN) is adopted to examine the contribution of UB causative parameters (independent variables) to the UB (a dependent variable). Artificial neural network (ANN) is a parallel computation inference model that is comprised of input, hidden, and output layers with a number of mathematical elements called the artificial neuron. The neurons in each layer are fully interconnected and the strength of the connection is expressed with a weight value. In the ANN model, dependent variables, i.e., inputs, are set in the input layer while the independent variable,

i.e., output, is placed at the output layer. The hidden layer is located between the input and the output layer. The artificial neurons in the input and output layer are interconnected through neurons in the hidden layer.

The UB prediction ANN model consisted of ten inputs, forty hiddens, and one output neuron. The hyperbolic tangent function was used as the transfer function in the forward pass while Levenberg-Marquardt (LM) algorithm (Levenberg 1944; Marquardt 1963) was employed as the learning function in the backward pass of the model training stage. $70 \%$ of the collected datasets were randomly allocated to the training stage while $15 \%$ of each remaining datasets were used for the validation and the test stage. The model trained with 100 iterations and the root-mean-square error (RMSE) in training stage was $1.90 \mathrm{E}-2$ and the test resulted with the correlation coefficient of 0.719 . 


\section{Parameter Contribution Analysis of UB Prediction ANN Model}

The UB prediction ANN model had achieved a statically significant result which facilitates to investigate the inputs and output sensitivity of the model. Often ANN is treated as 'a black box' as it is difficult to demonstrate how the model is optimized. Thus, some researches and engineers hesitate to adopt the ANN even it has been successfully utilized in many studies through various disciplines. To illuminate the model optimization process of ANN, various methods were developed e.g., Garson's algorithm (Garson 1991), connection weights algorithm (CWA) (Olden and Jackson 2002), Partial derivatives (PaD) method (Dimopoulos et al. 1995), Relative Strength of Effect (RSE) (Yang and Zhang 1998), and profile method (PM) (Lek et al. 1995). The Garson's algorithm and CWA can be categorized as the connection weights based algorithms while $\mathrm{PaD}, \mathrm{RSE}$, and $\mathrm{PM}$ can be called as the sensitively based algorithms.

In this study, the profile method is used as it investigates the entire range of inputs and output combinations. The percentage of a predicted uneven break when all inputs are set their 80th except GAQ (GAQ, 80th) was computed at the entire range of GAQ. The profiling process for GAQ was conducted in other ranges, i.e., 60th, 40th, and 20th, of remaining input variables. The profile method results of all ten input parameters of the UB prediction ANN model is shown in Appendix 1. Appendix 1-a, b, c, d, e, f, g, h, i, and j are profiling results of 10 inputs, and the overall sensitivity is demonstrated in Appendix 1-k.

\section{Discussion}

Through the PM application, the sensitivity of 10 UB causative factors to UB phenomenon has been analyzed. Two geological parameters, i.e., GAQ and GSK, revealed to have the relatively high effect to UB than other parameters by achieving a sensitivity of $20.48 \%$ and $18.12 \%$ respectively. Appendix 1-a shows the PM results of GAQ and the percentage of overbreak (UBP) decreased as the quality of rock becomes better. Appendix 1-b demonstrates the variance of UBP over the entire range of GSK which implies that UBP tends to decrease as the stope is getting deeper. The SAR (stope aspect ratio) shows $12.40 \%$ of contribution to UBP and the results are graphed in Appendix 1-c. The SAR shows a proportional relationship to UBP which indicates that the overbreak likely occurs in broader stope. The proportional trend of SAR over UBP in 60th and 80th are much steeper than other ranges which means the SAR (aspect ratio of stope) influences more in good rock condition. In succession, BSB revealed to have $10.41 \%$ of contribution to UBP which is shown in Appendix 1-d.

Table 2. Key findings of ten UB causative parameters investigated by the profile method (PM)

\begin{tabular}{l|c|l}
\hline Factor & Con. $\%$ & Key findings \\
\hline GAQ & $20.48 \%$ & The better the rock quality, the less the percentage of overbreak \\
\hline GSK & $18.12 \%$ & The deeper the stope, the less the percentage of overbreak \\
\hline SAR & $12.40 \%$ & The wider the stope, the more the percentage of overbreak \\
\hline BSB & $10.41 \%$ & The longer the ring burden, the more the percentage of overbreak \\
\hline SPT & $8.20 \%$ & The bigger the stope size, the more the percentage of overbreak \\
\hline SPF & $7.26 \%$ & The overbreak increases when the powder factor is increased \\
\hline BHD & $6.99 \%$ & The bigger the blasthole dia., the more the percentage of overbreak \\
\hline BHL & $6.13 \%$ & The longer the length of blasthole, the less the percentage of overbreak \\
\hline SOB & $5.25 \%$ & The percentage of overbreak is increased when the stope is blinded \\
\hline BAN & $4.77 \%$ & $\begin{array}{l}\text { The percentage of overbreak is increased with the parallel blasthole } \\
\text { pattern than the fanned pattern }\end{array}$ \\
\hline
\end{tabular}

The UBP is generally increased with increasing BSB except for the range of 40th which can be interpreted as the more overbreak would occur when the ring burden is longer. Next contributor to UBP is SPT that shows the overall sensitivity of $8.20 \%$. As observed in Appendix 1-e, except the remaining parameter range of 40th, UBP generally increased when stope size is bigger. Appendix 1-f is PM results of BPF (powder factor) with the overall contribution of $7.26 \%$. The BPF shows relatively high sensitivity in the range of the remaining parameters in 60th and 80th. As the rock quality, i.e., GAQ is the highest contributor to UBP form this study, the result of BPF can be interpreted as the leverage of BPF to overbreak is higher in the poor rock than the excellent quality rock. The PM results of the blasthole diameter (BHD) is shown in Appendix 1-g which has $6.99 \%$ of overall contribution to 
UBP. The overbreak is likely increased in $89 \mathrm{~mm}$ (3.5 in.) blast hole than $76 \mathrm{~mm}$ (3 in.) expect the remaining parameter range of 20th. Appendix 1-h demonstrates the relations between the blasthole length (BHL) and UBP. The overall sensitivity of BHL to UBP is calculated as $6.13 \%$, and it shows that the percentage of overbreak (UBP) is generally decreased in longer blasthole. The next influential contributor to UBP is SOB (opened or blind of the stope) with the overall contribution of $5.25 \%$ as shown in Appendix 1-i. The magnitude of overbreak is gradually increased in the blind stope except for the 20th of remaining parameter range. BAN (angle difference between hole and wall) has the overall contribution of $4.77 \%$ to the UBP, and the tendency is demonstrated in Appendix $1-\mathrm{j}$. Considering GAQ as the most influential contributor to UB phenomenon, the amount of overbreak is likely increased in the parallel drilling with the stope wall than the fanned pattern drilling. Finally, the overall contribution of the ten UB causative inputs to UBP is shown in Appendix 1-k. The key findings from the profile method (PM) application are summarised in Table 2.

\section{Conclusion}

The overbreak and underbreak (UB: uneven break) are unavoidable in underground stope production where the drill-and-blast is employed. A thorough examination of UB causative factors is essential to reveal the causing mechanism to minimize the unfavorable phenomenon. In this study, the contribution of ten UB causative factors to the percentage of the uneven break has been studied by investigating inputs and output sensitivities of a published UB prediction ANN model. The UB prediction ANN model is established using 1067 datasets and achieved the correlation coefficient of 0.71 . The sensitivity of the ANN model inputs and output is investigated using profile method (PM) which can thoroughly study the entire ranges of inputs and output relations. The result of PM method shows that the uncontrollable geological parameters, i.e., GAQ and GSK, revealed to have more influence than other blasting and stope design parameters as the overall contribution of $20.48 \%$ and $18.12 \%$ respectively. In succession, the contribution of SAR and BSB to UBP were $12.40 \%$ and $10.41 \%$ respectively. The other parameters, i.e., SPT, SPF, BHD, BHL, SOB, and BAN demonstrated less than $10 \%$ of contribution to the percentage of uneven break (UBP).

The mechanism of the overbreak and underbreak due to the dynamic blasting loads is exceptionally complex, and the exact causing parameters and their contributions have not been clearly discovered. The study attempted to reveal the contributions of ten key causing factors to overbreak and underbreak phenomenon in the underground stope blasting. The findings through the study can be used as a reference for design, production, and reconciliation of the underground stope production.

\section{Appendix 1}

The result of sensitivity analysis of the UB prediction ANN model. (BHL: Average length of blasthole, BPF: Powder factor, BAN: Angle difference between hole and wall 

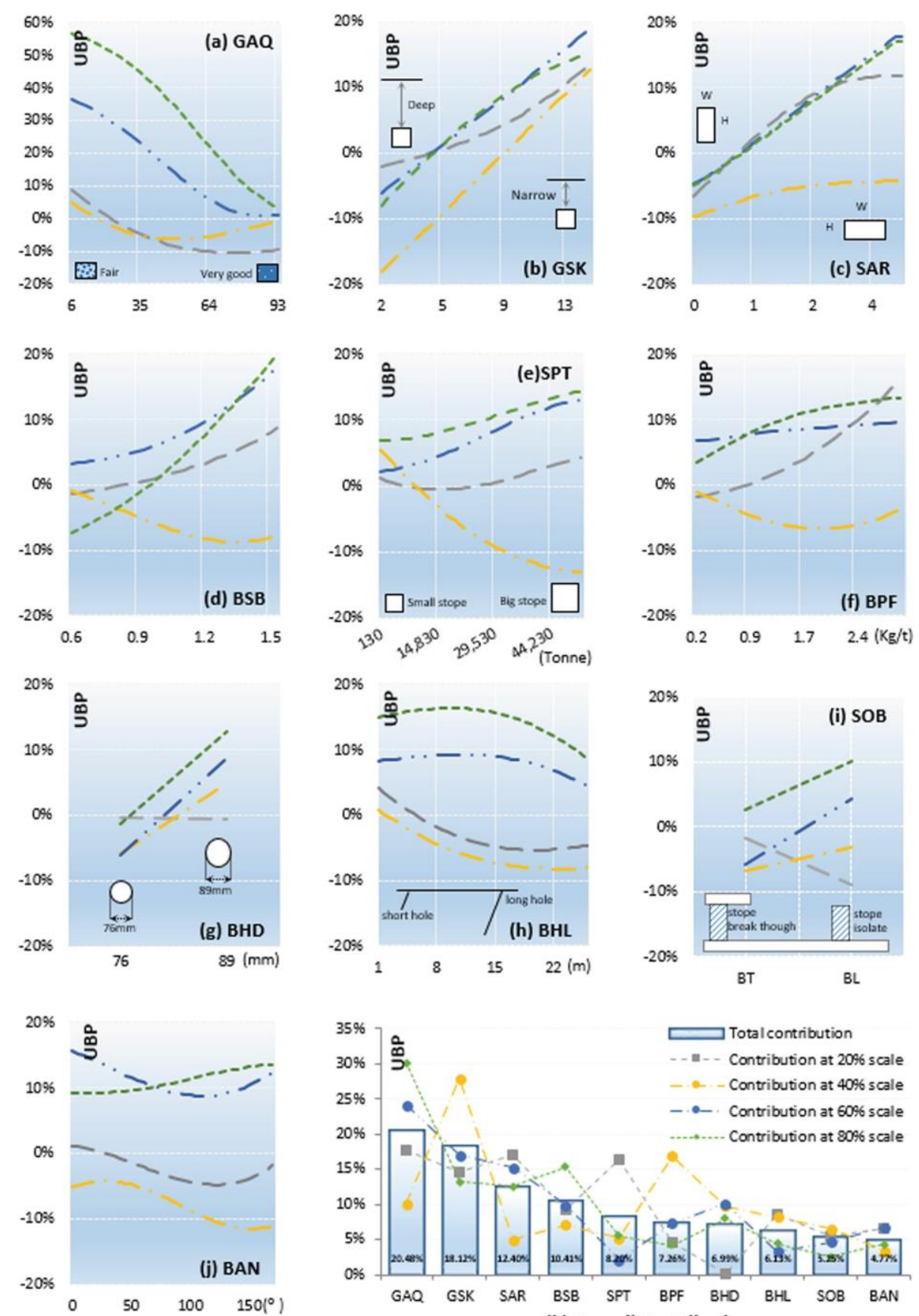

(k) Overall Contribution

\section{References}

Barton, N.R., Lien, R., Lunde, J.: Engineering classification of rock masses for the design of tunnel support. Rock Mech. 6, 189-236 (1974). Southern Nevada: Geological Society of America Bulletin 88, 943-959

Bieniawski, Z.T.: Engineering classification of jointed rock masses. Civ. Eng. South Afr. 15(12), 335-343 (1973)

Bieniawski, Z.T.: Geomechanics classification of rock masses and its application in tunnelling. Paper presented at the Advances in Rock Mechanics, Proceedings of the 3rd International Society of Rock Mechanics Congress, Denver, Colorado (1974)

Dimopoulos, Y., Bourret, P., Lek, S.: Use of some sensitivity criteria for choosing networks with good generalization ability. Neural Process. Lett. 2(6), 1-4 (1995)

Garson, G.D.: Interpreting neural-network connection weights. AI Expert 6(4), 46-51 (1991)

Germain, P., Hadjigeorgiou, J.: Influence of stope geometry and blasting patterns on recorded overbreak. Int. J. Rock Mech. Min. Sci. 34(3), 115.e111-115.e112 (1997). https://doi.org/10. 1016/S1365-1609(97)00219-0

Jang, H.: Unplanned dilution and ore-loss optimisation in underground mines via cooperative neuro-fuzzy network. Ph.D., Curtin University, Kalgoorlie, WA, Australia (2014)

Jang, H., Topal, E., Kawamura, Y.: Decision support system of unplanned dilution and ore-loss in underground stoping operations using a neuro-fuzzy system. Appl. Soft Comput. 32, 1-12 (2015a) 
Jang, H., Topal, E., Kawamura, Y.: Unplanned dilution and ore loss prediction in longhole stoping mines via multiple regression and artificial neural network analyses. J. South Afr. Inst. Min. Metall. 115, 449-456 (2015b)

Jang, H., Topal, E., Kawamura, Y.: Illumination of parameter contributions on uneven break phenomenon in underground stoping mines. Int. J. Min. Sci. Technol. 26(6), 1095-1100 (2016)

Jang, H.D.: Unplanned dilution and ore-loss optimisation in underground mines via cooperative neuro-fuzzy network. Ph.D. Dissertation, Western Australian School of Mines, Curtin University, Kalgoorlie, Western Australia, Australia (2014)

Lang, B.D.A.: Span design for entry-type excavations. Master, University of British Columbia, Vancouver, Canada (1994)

Lek, S., Belaud, A., Dimopoulos, I., Lauga, J., Moreau, J.: Improved estimation, using neural networks, of the food consumption of fish populations. Mar. Freshw. Res. 46(8), 1229-1236 (1995)

Levenberg, K.: A method for the solution of certain problems in least squares. Q. Appl. Math. 2, 164-168 (1944). doi:citeulikearticle-id:1951284

Marquardt, D.W.: An algorithm for least-squares estimation of nonlinear parameters. J. Soc. Ind. Appl. Math. 11(2), 431-441 (1963)

Mathews, K.E., Hoek, E., Wyllie, D.C., Stewart, S.: Prediction of stable excavation spans for mining at depths below $1000 \mathrm{~m}$ in hard rock. In: Paper presented at the CANMET DSS Serial No: 0sQ80-00081, Ottawa (1981)

Nickson, S.D.: Cable Support Guidelines for Underground Hard Rock Mine Operations. University of British Columbia, Vancouver, Canada (1992)

Olden, J.D., Jackson, D.A.: Illuminating the "black box": a randomization approach for understanding variable contributions in artificial neural networks. Ecol. Model. 154(1), 135- 150 (2002)

Pakalnis, R.C.T.: Empirical stope design at Ruttan mine. In: Paper presented at the Department of Mining and Minerals Processing, Vancouver (1986)

Pakalnis, R.C.T., Hughes, P.B.: Sublevel Stoping. In: Darling, P. (ed.) SME Mining Engineering Handbook, 3rd edn. Society for Mining, Metallurgy, and Exploration, Inc., United States of America (2011)

Potvin, Y.: Empirical open stope design in Canada. Ph.D., University of British Columbia, Vancouver, Canada (1988)

Stewart, P., Slade, J., Trueman, R.: The effect of stress damage on dilution in narrow vein mines. In: Paper presented at the 9th AusIMM Underground Operators Conference 2005 (2005)

Stiehr, J.F., Dean, J.: ISEE blasters' handbook, pp. 442-452. International Society of Explosives, Cleveland (2011)

Yang, Y.-J., Zhang, Q.: The application of neural networks to rock engineering systems (RES). Int. J. Rock Mech. Min. Sci. 35(6), 727-745 (1998) 